\title{
LA DECONSTRUCCIÓN DEL ESTADO AUTONÓMICO
}

\author{
VICENTE GARRIDO MAYOL \\ Profesor Titular de Derecho Constitucional \\ Universidad de Valencia*
}

\author{
SUMARIO \\ I. Reformas estatutarias y respeto de la \\ Constitución. \\ II. Algunas cuestiones de dudosa constitu- \\ cionalidad. \\ III. ¿Hacia la deconstrucción del Estado au- \\ tonómico?
}

\section{REFORMAS ESTATUTARIAS Y RESPETO DE LA CONSTITUCIÓN}

La Constitución de 1978, aún desconstitucionalizando el modelo territorial, sentó las bases para dar solución al viejo problema de la llamada, durante mucho tiempo, "cuestión regional". Y en aplicación de sus prescripciones España se constituyó en un Estado autonómico, con una descentralización política de intensidad alta en el contexto del derecho comparado. Pero el modelo resultante se ha configurado teniendo en cuenta las previsiones constitucionales que conforman un sistema que no puede ser obviado con torcidas interpretaciones o aludiendo a lo que se conoce como mutación constitucional.

Es evidente que el modelo, inicialmente indefinido, ha ido paulatinamente cerrándose o delimitándose sobre la base de las previsiones constitucionales, y que en ese proceso de configuración han intervenido una pluralidad de factores que han ido apareciendo a lo largo de estos años y a los que pueden unirse, en un futuro, otros, que propicien nuevas etapas en las que se vaya perfilando nuestro modelo de descentralización política.

Sin duda alguna en ese proceso ha ocupado un papel relevante la tensión centro-periferia, característica de todo Estado políticamente descentrali-

* Presidente del Consejo Jurídico Consultivo de la Comunidad Valenciana. 
zado, más perceptible en aquellas Comunidades autónomas que cuentan con partidos nacionalistas.

Es evidente que hemos alcanzado una cultura autonómica hoy irreversible, y llegado a un punto de estabilidad, sólo perturbado fundamentalmente, por las reivindicaciones de los nacionalistas vascos catalanes, y en menor medida, gallegos — surgidas especialmente tras la equiparación competencial nacida de los Pactos de 1992-, que persiguen que sus Comunidades sean tan diferentes como lo fueron al principio del proceso. En tal sentido cabe citar las Declaraciones de Barcelona, Gasteiz y Santiago, que se producen entre julio y octubre de 1998, propiciadas por la reunión conjunta del PNV, CiU y BNG, con las que pretendían abrir nuevas vía de reflexión sobre el modelo de Estado tendentes al reconocimiento jurídico-político del carácter plurinacional con una estructura competencial que haga efectivo tal reconocimiento. Tales declaraciones fueron contestadas por la de Mérida, en octubre de 1998, suscrita por los Presidentes de las Comunidades de Andalucía, Extremadura y Castilla-La Mancha en la que rechazaron las intenciones tendentes a cuestionar la cohesión garantizada en la Constitución y el intento de crear privilegios o desigualdad entre los españoles.

Y es que, como ha destacado Carreras ${ }^{1}$, los partidos nacionalistas vascos y catalanes, necesitan, por su propia naturaleza, que el modelo estructural esté permanentemente abierto ya que es consustancial a su ideología política el aumento de competencias. Y añado yo: un aumento de competencias no generalizado, pues de otro modo, la consecución de lo pretendido les genera insatisfacción.

Pero cuando determinadas reivindicaciones exceden de lo que razonablemente cabe entender comprendido en la Constitución, lo correcto constitucionalmente es plantear la reforma constitucional y alcanzar el consenso necesario para ello.

Como ha advertido Luciano Parejo la combinación de la idea de la «desconstitucionalización" del modelo territorial con el llamado principio dispositivo al servicio de la potenciación del papel del estatuto de autonomía como parte de un específico y difuminado "bloque de la constitucionalidad", el referido a la organización territorial del Estado, comporta no pocos riesgos ${ }^{2}$.

Sin duda alguna ha sido la reforma del Estatuto de Cataluña la que ha provocado nuevos debates sobre viejos problemas que se creían superados, pues la reforma del Estatuto de la Comunidad Valenciana,-la primera que se

1 DE CARRERAS SERRA, F. "El sistema autonómico español: ¿Existe un modelo de Estado?", Asimetría y cohesión en el Estado autonomico, 1997, pág. 103.

2 PAREJO ALFONSO, L. "La organización territorial del Estado, ¿proceso a continuar u obra a culminar?" Justicia administrativa, n. ${ }^{\circ} 31,2006$, págs, 5 y ss. Tales riesgos los concreta en la conversión en estructurales de previsiones constitucionales con la finalidad meramente fundacional y, por tanto, transitoria; en el trastocamiento de la economía interna del bloque ConstituciónEstatutos de autonomía por otorgamiento a éstos de una posición materialmente constituyente; y en la conversión de la interpretación constitucional cualificada, - la cumplida por el Tribunal Constitucional- en norma materialmente constitucional por la vía de su incorporación a los Estatutos de autonomía. 
aprobó durante la VIII Legislatura-, no planteó serios problemas de constitucionalidad ${ }^{3}$.

No estoy muy seguro de si era necesario reformar muchos de los Estatutos que lo han sido durante la VIII Legislatura o, en todo caso, de haber acometido reformas tan profundas, abordando cuestiones que han generado no pocas tensiones políticas y notables discrepancias jurídicas.

El rosario de recursos de inconstitucionalidad planteados ante el Tribunal Constitucional así lo pone de manifiesto, llegando a producir además, curiosas situaciones. Unas Comunidades frente a otras, en defensa de derechos cuyo ejercicio debe regularse en instancias estatales; el Defensor del Pueblo y el principal partido de la oposición a nivel nacional, han impugnado preceptos del Estatuto de Cataluña, aquietándose ante similares preceptos del Estatuto de Andalucía; el Tribunal Constitucional, no ha acumulado por motivos por todos conocidos, los recursos interpuestos contra un mismo Estatuto; maniobras en el Tribunal Constitucional que afectan al juego de las mayorías en su seno...

El resultado nos lleva a recordar épocas pasadas: los grandes avances de nuestro Estado autonómico han estado jalonados por amplios pactos a nivel nacional; así ocurrió en 1981 y en 1992. Ahora temas como la financiación, el agua, la Administración de Justicia, la gestión de los tributos o la configuración de los órganos constitucionales del Estado en torno a los cuales hay fuertes discrepancias, ponen de manifiesto la necesidad de una reposada discusión y de un consenso a nivel estatal. $\mathrm{O}$, en todo caso, pudieron plantearse para una reforma de la Constitución, anunciada al comienzo de la VIII Legislatura.

Como ha advertido Álvarez Conde ${ }^{4}$ cualquier reforma estatutaria afecta al Estado en su conjunto, pues las Comunidades autónomas son también Estado. Las reformas estatutarias no son un ejercicio de poder constituyente y no pueden afectar a los contenidos exclusivos constitucionales. Los Estatutos están sujetos al principio de primacía constitucional y deben interpretarse de conformidad con ésta. Lo contrario no son sino razonamientos jurídicos que tratan de enmascarar determinadas posiciones políticas.

Por ello es de suma importancia el criterio del Tribunal Constitucional en relación con los recursos de inconstitucionalidad ${ }^{5}$ formulados contra el Estatuto de Cataluña. No voy a abundar ahora sobre la naturaleza jurídica de los Estatutos de autonomía y su necesaria acomodación a la Constitución. Por eso sorprende a estas alturas, que haya quienes se alarmen de que quienes

3 Fue voluntad de las fuerzas políticas mayoritarias en las Cortes Valencianas y en las Cortes Generales - el PP y el PSOE_, que la reforma se acomodara a la Constitución sin necesidad de recurrir a forzadas interpretaciones. No obstante, el Estatuto valenciano fue impugnado ante el Tribunal Constitucional por las Comunidades de Aragón y Castilla-La Mancha al cuestionar el contenido del art. 17.1, sobre reconocimiento del derecho de redistribución de aguas de cuencas excedentarias. Como es sabido, dichos recursos de inconstitucionalidad fueron desestimados por Sentencias de 12 de diciembre de 2007.

4 ÁlVAREZ CONDE, E., Reforma Constitucional y Reformas Estatutarias, Iustel Madrid, pág. 170.

5 Recursos formulados, como es sabido, por el Grupo Parlamentarios Popular del Congreso de los Diputados, por el Defensor del Pueblo y por la Comunidad Valenciana, Aragón, Islas Baleares, La Rioja y Murcia. 
tienen legitimación para ello, impugnen aquellas normas con rango de ley, como los Estatutos de autonomía, que consideren contrarias a la Constitución e incluso aboguen, como Pérez Royo ${ }^{6}$, por la retirada de tales recursos, argumentando que "no es posible que un órgano que carece de legitimación democrática directa pueda resolver un recurso como el que interpuso el $P P$, sin que su legitimidad democrática se resienta...El daño que se le ha becho al TC ha sido enorme", y señalando que "...sería mucho lo que ganariamos todos si el TC no tuviera que pronunciarse...".Sorprenden las palabras del ilustre profesor como sorprenden las más recientes del Presidente de la Generalitat de Cataluña al afirmar que "El Estatuto es una Ley Órgánica y además un pacto politico que no pueden tumbar los Tribunales" ${ }^{7}$. No se puede obviar que son legión los juristas, —entre los que modestamente me cuento-, que dudan, cuando no afirman categóricamente, de la constitucionalidad del Estatuto de Cataluña. Y ello no obstante haber sido ratificado mediante referéndum,-por cierto, con raquítica participación-, por el pueblo catalán, pues no podemos olvidar que nuestro sistema jurídico-constitucional prevé la posibilidad de que todas las normas con rango de ley puedan ser enjuiciadas por el Tribunal Constitucional. En este sentido, Portero Molina ${ }^{8}$ ha afirmado que "La opinión de que el Tribunal Constitucional no debería de enjuiciar el Estatuto catalán, porque el electorado ya se pronunció a su favor, es constitucionalmente insostenible".Y añade, con razón, que "La reforma estatutaria no es solo cuestión de pura voluntad política. Es una operación regulada por el derecho. Es la reforma de una norma que vive en un ordenamiento jurídico presidido por la norma suprema. Por eso el procedimiento y el contenido de la reforma no pueden ser jurídicamente opuestos a la Constitución. El TC es quien juzga si la reforma estatutaria ha sido correcta..." recordando, como se enseña a los estudiantes de derecho en el primer curso de la carrera, que "Ninguna norma puede ser contraria a la Constitución porque, si pudiera serlo, la Constitución dejaría de ser suprema" y que "el electorado catalán no es el soberano en Cataluña. Lo es el pueblo español sobre todo el territorio del Estado".

La Sentencia que dicte el Tribunal Constitucional va a ser esencial para delimitar lo que se ha venido a denominar una nueva reformulación de nuestro Estado autonómico o sobre la llamada "constitución territorial". Bien es verdad que no faltan agoreros que predicen una resolución más política que jurídica, más de compromiso que de estricto examen de adecuación constitucional, una Sentencia asexuada que antes que solucionar problemas nos lleve a nuevos embrollos. Pero descalificar apriorísticamente al máximo intérprete de la Constitución no resulta adecuado a la ortodoxia jurídica y tan reprochable es lamentarse de la intervención del Alto Tribunal como descalificar antici-

6 Así, J. PÉREZ ROYO en "Una petición razonable», (El Pais, 25.4.2009) se refiere a la formulada por La Vanguardia, dirigida al líder del PP, para que retirase el recurso de inconstitucionalidad interpuesto por su Grupo Parlamentario.

7 El País, 19.7.2009.

8 PORTERO MOLINA, J.A., "Una opinión insostenible e incomprensible", Levante-EMV, 24.4.2009. 
padamente lo que pueda resolver. Es evidente que las Sentencias del Constitucional, como las de cualquier otro órgano que ejerce jurisdicción, no gozan de infalibilidad y pueden ser analizadas y criticadas, pueden dar lugar a discrepancias jurídicas y a debates académicos, pero en todo caso constituyen la opinión fundamentada de quien tiene la última palabra para resolver un litigio y, se deben acatar y cumplir. De cualquier forma, obvio es decirlo, las que resuelvan los recursos formulados contra el Estatuto de Cataluña van a tener una trascendencia enorme en la configuración del Estado autonómico, pues son muchas las cuestiones planteadas cuyo tratamiento, en uno u otro sentido, pueden afectar profundamente a la estructura territorial del Estado.

\section{ALGUNAS CUESTIONES DE DUDOSA CONSTITUCIONALIDAD.}

Contra el Estatuto de Cataluña se presentaron un total de siete recursos de inconstitucionalidad. Los de las Comunidades autónomas atacan cuestiones puntuales como las relativas al archivo de la Corona de Aragón (Comunidad Valenciana, Aragón e Islas Baleares), al agua (Murcia, La Rioja y también la Comunidad Valenciana) o a las previsiones de inversiones del Estado de Cataluña (Comunidad Valenciana). Los del Defensor del Pueblo y, especialmente, de los Diputados del Partido Popular son notablemente mas extensos y tachan de inconstitucionales numerosos preceptos del nuevo Estatuto Catalán. De ahí que el Tribunal Constitucional tenga que dar cumplida respuesta a las impugnaciones formuladas, es de suponer que comenzando con la Sentencia correspondiente al recurso de los Diputados populares que, de alguna manera, condicionará la de los demás recursos en aquellas cuestiones que sean coincidentes.

No es objeto de este trabajo hacer un examen exhaustivo de cuantas tachas de constitucionalidad se han opuesto por los recurrentes. Pero la lectura del Estatuto de Cataluña invita a reflexionar entre otras, en torno a tres cuestiones de las que me ocupo a continuación: el sistema competencial; las cláusulas sobre inversiones del Estado (previstas no solo en el Estatuto de Cataluña, sino también en el de Andalucía); y algunas previsiones relacionadas con el agua.

Quizás cuando estas páginas se publiquen es posible que el Tribunal Constitucional ya se haya pronunciado al respecto, lo que no es inconveniente para que, previamente, exprese mi opinión al respecto.

\section{II.1. EL SISTEMA DEL «BLINDAJE» DE COMPETENCIAS}

Frente al modelo tradicional de los Estatutos originarios de atribución de títulos competenciales genéricos, —-modelo que sigue el vigente Estatuto valenciano-, los Estatutos catalán y andaluz cuartean las materias en submaterias para abrir posibilidades antes no imaginadas dando lugar a lo que se ha 
llamado "blindaje de competencias" de suerte tal que se pretende limitar la acción del Estado, en ejercicio de sus propias competencias. Y tal blindaje se lleva a cabo incluso contrariando, a mi juicio, el criterio del Tribunal Constitucional expresado en sus resoluciones tendentes a delimitar el contenido de diversos títulos competenciales.

Se puede decir, por tanto, que las reformas estatutarias operadas durante la VIII Legislatura han producido, desde el punto de vista competencial, fundamentalmente dos modelos que representan los Estatutos valenciano y catalán respectivamente?

Así el Estatuto de Cataluña dedica a sus competencias un total de 63 artículos, mientras que el de la Comunidad Valenciana tiene un Título IV, sobre "Las competencias" con tan sólo 10 artículos. Está por hacer un estudio detallado sobre cual de los Estatutos atribuye más competencias a sus respectivas Comunidades. O dicho de otro modo: si los títulos genéricos del Estatuto valenciano, integran los específicos del catalán.

Con el modelo catalán se ha pretendido, según se ha dicho ${ }^{10}$, incrementar la calidad competencial, lo que en la práctica se ha traducido en un blindaje frente a la tendencia competencial expansiva del Estado, auspiciado por una interpretación jurisprudencial favorable en tal sentido.

Se persigue, con ello, evitar que el Estado, por medio de la legislación básica, más que fijar grandes principios a los que se deban conformar las normas autonómicas, precise y concrete de forma amplia y detallada los contenidos de una determinada materia en detrimento de las potestades autonómicas. E igualmente, que el Estado no abuse de los llamados títulos horizontales como la coordinación de la planificación general de la actividad económica (art. 149.1.13 CE), o la regulación de las condiciones básicas que garanticen la igualdad de todos los españoles en el ejercicio de los derechos y en el cumplimiento de los deberes constitucionales (art. 149.1.1 CE), para invadir el ámbito competencial genuinamente autonómico.

Joaquín Tornos ${ }^{11}$ ha señalado que con la técnica utilizada por el Estatuto de Cataluña se pretende que en la resolución de futuros conflictos en los que se discuta la constitucionalidad de normas estatales básicas se apliquen los criterios establecidos en la norma estatutaria para determinar la constitucionalidad o no de la norma enjuiciada. O sea, se trata de mermar la capacidad del Tribunal Constitucional, constitucionalmente reconocida, por medio de las previsiones de un Estatuto.

9 Sobre las diversas técnicas estatutarias de distribución de competencias vid. mas ampliamente, TUR AUSINA, R. "El sistema competencial valenciano tras la reforma estatutaria de 2006, Análisis al hilo de la reciente oleada de reformas estatutarias", Modelo de Estado y Reformas de los Estatutos, V. GARRIDO MAYOL (Coord), Fundación Profesor Manuel Broseta, Valencia, 2007, págs. 225 y ss.

10 ALBERTI, E. "El Blindaje de las competencias y la reforma estatutaria", Revista catalana de Pret püblic, n. ${ }^{\circ} 31,2005$, p.3.

11 "La nueva configuración de las competencias compartidas en el Estado de autonomías. Algunos problemas que plantea su aplicación", Revista General de Derecho Constitucional, n. ${ }^{\circ}$, 2008. 
Además, se ha querido determinar con precisión qué materias y submaterias forman parte de la competencia autonómica de desarrollo legislativo, para evitar que esas materias pasen a ser englobadas dentro de la competencia legislativa estatal. Se trata de un doble juego, dice Tornos: por una parte, reducir lo básico a una regulación de principios y por otra, establecer que determinadas materias y submaterias no podrán ser reguladas en su totalidad por la norma estatal al formar parte de la competencias autonómica de desarrollo normativo.

$\mathrm{Al}$ respecto hay que recordar que el Tribunal Constitucional ha advertido que "...cuando la Constitución o un Estatuto declara una atribución de competencias sobre una materia no es necesario que relacione la lista de facultades concretas que comprende esa competencia, ni sería posible bacerlo, y bay que deducir estas diversas facultades de su posible inclusión en la materia sobre la cual recae la competencia" (STC 71/83).

Conviene advertir desde este momento, que concretar las submaterias que engloban una materia y reseñar las concretas facultades que derivan de una determinada potestad en relación a una materia no comporta per se, ni un aumento de las competencias ni una mayor calidad de aquéllas pues los títulos competenciales genéricos pueden acoger los específicos. Además, dicha técnica de la minimización competencial puede entrañar no pocos riesgos a quien de ella pretenda beneficiarse pues puede darse el caso de que no concretada una submateria de un título genérico, pueda entenderse que se carece de competencia sobre ella. El recurso al detalle, aparte otras disfunciones, como veremos, puede, por tanto, provocar restricciones en el campo de actuación de la Comunidad autónoma sobre concretos sectores materiales no mencionados en su Estatuto. Como ha señalado Tur Ausina ${ }^{12}$, podría producirse una petrificación que con el tiempo limitara la capacidad de maniobra estatutaria y exigiera reformas de la norma institucional básica o bien puntuales leyes de transferencias.

Veamos un ejemplo: en materia de Cajas de Ahorro, el artículo 49.1.34. ${ }^{\mathrm{a}}$ del Estatuto valenciano establece que la Generalitat tiene competencia exclusiva en materia de Cajas de Ahorro, de acuerdo con lo dispuesto en la legislación básica del Estado (puesto que según el artículo 149.1, 11. ${ }^{\mathrm{a}}$ y 13. a , el Estado tiene competencia exclusiva respecto de las bases de la ordenación del crédito, banca y seguros y de la planificación general de la actividad económica $)^{13}$.

Por el contrario, el artículo 120 del Estatuto de Cataluña, con un texto amplio y prolijo, aun estableciendo que se respetan las competencias del Estado, concreta lo que tal competencia en materia de Cajas de Ahorro incluye.

Con tal redacción el Estatuto trata de subdividir la materia Cajas de Ahorro en diferentes submaterias. Ello es a mi juicio, criticable, pues no es posible que un Estatuto defina, con carácter general, en materias compartidas, el

12 Op. cit., pág. 238.

13 Vid. SSTC 48 y 49/1988 
alcance de una competencia estatal básica actuando como norma interpretativa de la Constitución.

Tornos ${ }^{14}$ defiende la constitucionalidad de tal proceder al indicar que el legislador estatal no tiene porqué modificar su legislación básica válida y vigente en el resto del Estado, pues el nuevo alcance de lo básico, material y formal, queda en principio restringido a su concreción interna en Cataluña. O sea, según esta tesis, lo que es básico para Galicia, no lo es para Cataluña, pues en esta Comunidad autónoma lo básico podrá ser desplazado por normas que emanen de su Parlamento en ejercicio de su competencia de desarrollo legislativo.

¿No es esto un despropósito? ¿No resulta disparatado? Quien así argumenta aun dice más: si el legislador estatal quiere hacer uso de su potestad para dictar normas básicas no podrá desconocer el contenido del Estatuto de Cataluña y en todo caso, deberá dar un tratamiento diferenciado al alcance de lo básico. Así, un precepto estatal no será básico en Cataluña pero si en el resto de Comunidades Autónomas.

Seamos serios: un precepto estatal o es básico o no lo es, pero no puede serlo en unas partes del territorio y en otras no.

Otro ejemplo que pone de manifiesto el complejo panorama que presenta la nueva configuración competencial de los nuevos Estatutos lo encontramos en el establecimiento de las demarcaciones registrales y notariales.

El artículo 149.1.8. ${ }^{a}$ de la Constitución atribuye al Estado la competencia exclusiva en materia de legislación civil que incluye, en todo caso, la ordenación de los registros e instrumentos públicos. En interpretación de dicho título competencial, el Tribunal Constitucional, en sus Sentencias 97/1989 y 87/1989, sentó la doctrina de que las competencias asumidas por los distintos Estatutos de autonomía sólo hacían referencia al nombramiento de los Registradores y Notarios y a la participación en las demarcaciones registrales y notariales.

Por ello, desde la perspectiva de la delimitación competencial es conveniente tomar en consideración la entrada en vigor del Estatuto de Cataluña, puesto que si bien el Estatuto en su versión originaria atribuyó a la Generalitat de Cataluña la facultad de participación en el establecimiento de las demarcaciones registrales y notariales, el artículo 147.1 c) del vigente Estatuto atribuye a la Generalitat de Cataluña la competencia para el establecimiento de las demarcaciones notariales y registrales, incluida la determinación de los distritos hipotecarios y de los distritos de competencia territorial de los notarios. En los mismos términos se expresa el art. 77,1 del nuevo Estatuto de Andalucía. En relación con la Comunidad Valenciana, las Islas Baleares y Castilla y León, sus vigentes Estatutos prevén la participación de la Comunidad en la determinación de las demarcaciones registrales en los mismos términos que los respectivos preceptos estatutarios precedentes. Respecto a la Comunidad Autónoma de Aragón, el anterior Estatuto de autonomía no preveía la participación de dicha Comunidad en la fijación de las demarcaciones

14 Op. cit., pág. 6. 
registrales. El art. 78.2 del vigente Estatuto de Aragón, prevé la participación de la Comunidad Autónoma en la fijación de las demarcaciones correspondientes a las Notarías y a los Registros de la propiedad y mercantiles, de acuerdo con lo previsto en las leyes generales del Estado.

Pero las previsiones estatutarias de Cataluña y Andalucía exigen plantearse el efecto que tendrán sobre las competencias del Estado para el establecimiento de las demarcaciones registrales y notariales, así como su repercusión en relación con la competencia de la Comunidad Valenciana en dicha materia.

Respecto a la competencia del Gobierno de la Nación, y en aplicación de la doctrina del Tribunal Constitucional expresada en la Sentencia 97/1989, de 30 de mayo, el artículo 147.1 c) del Estatuto de Cataluña se considera que podría alterar el orden de competencias al corresponder al Estado la fijación de la demarcaciones registrales como aspecto específico de la facultad de ordenación de los registros y, en igual modo, la delimitación de las demarcaciones notariales. Y sin que, en ningún caso, como se ha indicado, pueda interpretarse un precepto estatutario "de modo que altere el orden de competencias establecido en la Constitución (STC 39/1982, de 30 de junio)”. Además, como ha mantenido en reiteradas ocasiones el Tribunal Constitucional (Sentencia de 56/1990, entre otras) los Estatutos de autonomía, pese a su forma de Ley Orgánica, no son instrumentos ni útiles ni constitucionalmente idóneos, por su naturaleza y modo de adopción, para realizar las transferencias o delegaciones de facultades de una materia de titularidad estatal permitidas por el artículo 150.2 de la Constitución.

En concreto, en la materia de que tratamos — demarcaciones registrales y notariales - lo que ha hecho el Estatuto de Cataluña es aplicar la técnica del blindaje competencial, o la llamada "inclusión de perfiles competenciales", a fin de evitar la expansividad del legislador estatal y de forzar la función del Tribunal Constitucional al analizar el alcance de las competencias concretadas en dicho Estatuto, lo que adquiere mayor relieve cuando sobre una determinada materia el Tribunal Constitucional ya ha fijado su posición, como ocurre con la que es objeto de comentario, tal y como ha quedado expuesto.

El Consejo Consultivo de Andalucía, en su Dictamen 72/2006 sobre la Proposición de Reforma del Estatuto para Andalucía, aconsejó que el proyectado precepto sobre registros y notariado concretara la correspondiente competencia en la "ejecución" sobre "nombramiento de notarios y registradores, demarcaciones notariales y registrales" haciéndose eco de la advertencia del Tribunal Constitucional contenida en su citada Sentencia 97/89, que señaló que "la competencia estatal exclusiva en materia de demarcaciones registrales quedaría vacía de contenido si no pudiera efectuar, en ejercicio de aquella competencia, aspecto tan sustancial como la determinación de su ubicación y ámbito territorial..

También el Consejo Jurídico Consultivo de la Comunidad Valenciana, en su dictamen 506/2008, señaló que el expresado precepto del Estatuto de Cataluña —y el similar del Estatuto de Andalucía- podría adolecer de vicio de inconstitucionalidad por vulnerar el artículo 149.1.8. ${ }^{a}$ de la Constitución. 
Hay que advertir que todo lo indicado no empece a que nos planteemos la oportunidad de la conveniencia o no de que sean las Comunidades autónomas las que deberían determinar las demarcaciones notariales y registrales, cuestión que escapa del objeto de nuestra atención.

Podríamos detenernos en el análisis de otras materias cuya actual regulación en el Estatuto de Cataluña plantea el mismo problema apuntado: va mas allá de lo que el Tribunal Constitucional ha sentado como constitucionalmente adecuado.

Ante este panorama tan complejo sólo cabe confiar en la última palabra del Tribunal Constitucional, máximo intérprete de nuestra Carta Magna. Si tras un largo y costoso proceso de casi treinta años de jurisprudencia constitucional las piezas maestras del Estado autonómico podían considerarse asentadas, veremos si tras la Sentencia sobre el Estatuto de Cataluña continúan teniendo el significado y funcionalidad que hasta ahora se le había dado.

\section{II.2. LAS CLÁUSULAS ESTATUTARIAS SOBRE INVERSIONES ESTATALES}

Me sugieren esta reflexión las cláusulas sobre inversiones de los Estatutos de Cataluña y de Andalucía.

Las inversiones que anualmente proyecta realizar el Estado constituyen una de las partidas más importantes de los Presupuestos Generales del Estado. Podemos distinguir entre la inversión que afecta únicamente a aquellas Comunidades Autónomas a las que se destina, la inversión regionalizable, y la que afecta a todos los españoles por igual que constituye la inversión no regionalizable.

La Disposición Adicional Tercera del Estatuto de Cataluña, dispone que "La inversión del Estado en Cataluña en infraestructuras, excluido el Fondo de Compensación Interterritorial, se equiparará a la participación relativa del producto interior bruto de Cataluña con relación al producto interior bruto del Estado para un periodo de siete años...”.

Por su parte, la Disposición Adicional Tercera del Estatuto de autonomía de Andalucía, en su segundo apartado, prescribe que «la inversión destinada a Andalucía será equivalente al peso de la población andaluza sobre el conjunto del Estado para un período de siete años".

De esta manera se fija el criterio que ha de emplear el Estado al tiempo de cuantificar el importe de la inversión regionalizable en dichas Comunidades autónomas durante los siguientes siete años a su entrada en vigor.

Ambas Disposiciones tienen en común la fijación en sede estatutaria del criterio de inversión regionalizable del Estado en la respectiva Comunidad Autónoma, e imponer dicho criterio durante un mismo período de siete años. Ahora bien, difieren en el tipo de criterio que va a regir dicha inversión: así, mientras en Andalucía el criterio - como se ha indicado anteriormente- es el del peso de la población en el conjunto del Estado, en Cataluña el porcentaje de la inversión ha de ser igual al porcentaje que representa el PIB de la 
Comunidad con respecto al PIB nacional. Además, en el Estatuto de Cataluña, la inversión que se prevé lo es dejando aparte los fondos que puedan percibirse del Fondo de Compensación Interterritorial, mientras que la Disposición del Estatuto de Andalucía guarda silencio al respecto.

El contenido de ambas Disposiciones Adicionales ${ }^{15}$ plantea la cuestión de la posibilidad de introducir este tipo de cláusulas de porcentajes de reparto de las inversiones regionalizables estatales en los Estatutos de Autonomía.

Para ello hemos de partir, en primer lugar, del ámbito normativo de aplicación a las inversiones estatales que está constituido por la Ley Orgánica 8/1980, de Financiación de las Comunidades Autónomas, de 22 de diciembre (LOFCA), que se dictó en cumplimiento de lo dispuesto en el artículo 157.3 de la Constitución con la finalidad de garantizar el cumplimiento real de los principios de coordinación y solidaridad, así como los restantes principios constitucionales en materia económico-financiera. Concretamente, el artículo 16, apartado 10 de la LOFCA —en la versión dada por la ley Orgánica $7 / 2001$, de 27 de diciembre- dispone que "sin perjuicio de lo establecido en los apartados anteriores, las inversiones que efectúe directamente el Estado y el Sector Público Estatal se inspirarán en el principio de solidaridad".

Este precepto prevé, por tanto, lo que constituyen las inversiones directas del Estado en las Comunidades Autónomas, sujetando la actuación inversora al principio de solidaridad interterritorial.

Corresponde posteriormente al legislador estatal, conforme a lo dispuesto en la Ley estatal 47/2003, de 26 de noviembre, sobre Contabilidad y Presupuestos, proceder a la determinación de los concretos criterios de reparto de las inversiones regionalizables por medio de la Ley de Presupuestos del Estado. La atribución al Estado de la competencia para fijar los porcentajes de reparto de las inversiones se justifica en los títulos referidos de las "Bases y Coordinación de la planificación general de la actividad económica" (artículo 149.1.13) y "Hacienda General" (artículo 149.1.14. ${ }^{a}$ ) al afectar a la hacienda general y fundamentalmente a las directrices de política económica que para un determinado ejercicio o ejercicios presupuestarios se fijen por el Gobierno y las Cortes Generales.

Es necesario recordar que el artículo 134 de la CE atribuye al Gobierno la competencia para la elaboración de los Presupuestos Generales del Estado y a las Cortes Generales su examen, enmienda y aprobación. Unos presupuestos que incluirán la totalidad de los "gastos" del sector público estatal. De esta forma, cualquier compromiso de gasto, como pueda ser la política inversora del Estado, es competencia de las Cortes Generales expresada en las correspondientes leyes de presupuestos.

La previsión contenida en los Estatutos catalán y andaluz constituye un compromiso de gasto que se impone al Estado en materia de inversiones directas. Dichas cláusulas implican que durante siete años los presupuestos

15 Que fueron objeto de atención del Consell Jurídic Consultiu de la Comunitat Valenciana, en sus dictámenes 633/2006 y 543/2007. 
del Estado tienen que recoger, de forma imperativa, una inversión para Cataluña y Andalucía equivalente al "peso de su producto interior bruto" o al "peso de su población" respectivamente, cuando toda decisión en esta materia debe corresponder exclusivamente a las Cortes Generales de acuerdo con el principio de solidaridad y en función de las posibilidades reales del país en su conjunto ${ }^{16}$.

A mi juicio, no es el Estatuto de Autonomía la norma en la que deben fijarse y petrificarse decisiones políticas en materia de inversiones que correspondan al legislativo, y no obsta a ello el hecho de que el Estatuto se trate de una norma aprobada por las Cortes Generales mediante Ley Orgánica. Y es que el Estatuto no es una simple Ley Orgánica, sino la norma institucional básica de las Comunidades Autónomas que se aprueba por Ley Orgánica. Prueba de ello es que una vez aprobado el Estatuto ni el Estado ni la Comunidad autónoma pueden unilateralmente proceder a su modificación sin el concurso de las voluntades de ambos. Son normas jurídicas de naturaleza compleja con un singular procedimiento de elaboración y con un singular procedimiento de reforma. No son simples Leyes Orgánicas y por ello no pueden ser reformados como las Leyes Orgánicas, con la exclusiva voluntad del las Cortes Generales. Cualquier modificación exigiría necesariamente que fuese pactada entre el Estado y la Comunidad Autónoma respectiva. Y en el caso de los Estatutos de Cataluña y Andalucía, como en algunos otros, sometida a referéndum.

Si atendemos a lo argumentado con anterioridad, la previsión contenida en tales Disposiciones Adicionales implica que las Cortes Generales se encuentran condicionadas por ellas durante un largo plazo ( 7 años), sin que en ningún caso puedan modificar, en el ejercicio de sus facultades en materia de inversiones, el criterio de reparto sin la concurrencia de la voluntad de aquellas Comunidades, al haberse estatuido el criterio de reparto en una norma cuya modificación exige el concurso de voluntades del Estado y la Comunidad Autónoma. Nos encontramos ante normas que, aunque estatales desde la perspectiva de su aprobación, son indisponibles para el Estado, pues como ha quedado expuesto, el Estado no puede, por sí solo, modificar un Estatuto de autonomía ${ }^{17}$.

16 Puede verse, al respecto, la Ley 51/2007, de 26 de diciembre, de Presupuestos Generales del Estado para 2008, cuya Disposición Adicional Quincuagésima sexta contiene la aplicación de la metodología para el cumplimiento de la Disposición Adicional Tercera del Estatuto de Cataluña. Por su parte, la Disposición Adicional Quincuagésima de la misma Ley, contiene una previsión en relación con la Disposición Adicional Tercera del Estatuto de Andalucía.

17 El Gobierno de la Comunidad Valenciana ya ha anunciado que si el Tribunal Constitucional considera que la Disposición Adicional Tercera del Estatuto de autonomía de Cataluña es conforme con la Constitución, impulsará la reforma del Estatuto valenciano a fin de incluir una Disposición similar en los términos que resulten más beneficiosos para los valencianos. ¿Qué ocurriría si todas las Comunidades autónomas procedieran de igual modo? Será difícil explicar desde instancias estatales que las previsiones estatutarias válidas para unas Comunidades autónomas, no lo son para otras. Pero si cada Estatuto establece el criterio que mas conviene a su Comunidad, el caos está asegurado. 
Por el contrario, la Ley de Presupuestos Generales del Estado,-instrumento constitucional al que corresponde materializar y dar efectividad a las inversiones regionalizables - , es susceptible de modificación unilateral por las Cortes Generales en el ejercicio de su potestad legislativa.

De este modo, es a las Cortes Generales a quien corresponde, mediante la Ley General de Presupuestos y no otra norma, prever las inversiones estatales, la ponderación de los criterios de reparto y la cuantificación de su importe, atendiendo al principio de solidaridad interterritorial, así como a las posibilidades económicas del Estado y a las necesidades de las Comunidades Autónomas en cada momento.

En este punto resulta significativa la doctrina del Tribunal Constitucional recogida en la Sentencia 13/2007, de 18 de enero, en la que recuerda que la competencia en la determinación de los criterios de reparto del Fondo de Compensación Interterritorial, así como respecto de las participaciones en los ingresos del Estado, corresponde de forma exclusiva a las Cortes Generales; doctrina que resulta trasladable al reparto de las inversiones del Estado con destino a las Comunidades Autónomas. Así, en el fundamento jurídico n. ${ }^{\circ}$ de dicha Sentencia se señala que "este Tribunal no puede atender la pretensión de la Comunidad Autónoma andaluza de que la variable representada por el coeficiente de población se determine en el sentido que ella propone... porque con ello estaría adoptando una decisión eminentemente política que corresponde exclusivamente tomar a las Cortes Generales de acuerdo con el principio de solidaridad y en función de las posibilidades reales del país en su conjunto. A este respecto conviene traer a colación las afirmaciones que este Tribunal ha hecho en relación con las variables que establece el art. $16 \mathrm{LOF}$ CA para el reparto del Fondo de Compensación Interterritorial, en las que insistimos que era función exclusiva de las Cortes Generales, dentro de un amplio margen de apreciación, determinar la importancia de cada criterio en la distribución del citado recurso financiero, afirmaciones que resultan trasladables mutatis mutandis a las variables a que bace referencia el art. 13 LOFCA con relación a la participación en los ingresos del Estado. (...) es a las Cortes Generales a quienes corresponde la determinación del peso respectivo de cada criterio de distribución del FCI len el caso presente, del porcentaje de participación en los ingresos del Estadol, en apreciación que no puede verse sustituida por la de este Tribunal" (STC 183/1988, de 13 de octubre, F. 4). ..."La apreciación de la mayor o menor conveniencia técnica de emplear unos datos u otros (bien los últimos disponibles, bien los correspondientes al ejercicio inmediatamente anterior) corresponde al legislador, y la decisión adoptada por éste de acuerdo con criterios de oportunidad queda dentro del margen de actuación que le concede la LOFCA" (STC 183/1988, de 13 de octubre...".

Reitera el Alto Tribunal, en su fundamento jurídico 6. ${ }^{\circ}$, que "... es al Estado a quien corresponde, en el momento de establecer la participación de las Comunidades Autónomas en los ingresos transferibles, ponderar los intereses en juego, tanto los del conjunto de las Comunidades Autónomas como de los suyos propios, en virtud de la competencia exclusiva que sobre la materia le 
atribuye el art. 149.1.14...", y que "cuando la Constitución atribuye al Estado una competencia exclusiva lo hace porque bajo la misma subyace o, al menos, asi lo entiende el constituyente, un interés general, interés que debe prevalecer sobre los intereses que puedan tener otras entidades territoriales afectadas" (STC 40/1998, de 19 de febrero F. 30); y en el mismo sentido, STC 204/2002, de 31 de octubre F. 7). (...) En suma, es de competencia exclusiva del Estado, en ejercicio de la que le atribuye al efecto el art. 149.1.14 CE, no sólo el señalamiento de los criterios para el reparto de la participación que se les conceda a las Comunidades Autónomas en los ingresos estatales, sino también la concreción por Ley de esa participación (...)”.

Dicho cuanto antecede, la fijación del porcentaje de reparto de las inversiones regionalizables del Estado no ha sido ni debe ser una previsión estatutaria. Las inversiones del Estado para que resulten efectivas necesariamente han de estar previstas en los Presupuestos Generales del Estado que anualmente aprueban las Cortes Generales, y no es admisible que un Estatuto, o varios, predeterminen el contenido de tales presupuestos en contra de la competencia que al Gobierno y a las Cortes Generales les atribuye el artículo 134 de la Constitución, para su elaboración y aprobación. Y mucho menos cuando se vincula al Estado para un plazo de tiempo largo — siete añosencorsetando las decisiones políticas que en materia presupuestaria corresponden a las Cortes, en virtud del citado artículo 134 en relación con los artículos 149.1.13 y 149. 14 de la Constitución.

Pero es que, además, como se ha indicado con anterioridad, el artículo 16.10 de Ley Orgánica 8/1980, de 22 de septiembre, LOFCA, en la versión dada por la ley Orgánica 7/2001, de 27 de diciembre, dispone que "... las inversiones que efectúe directamente el Estado y el Sector Público Estatal se inspirarán en el principio de solidaridad.

El principio de "solidaridad entre todos los españoles" constituye uno de los fundamentales del orden económico en general. El Tribunal Constitucional, en su Sentencia 135/1992, señala respecto del principio de solidaridad que "Su contenido más importante es el financiero y en tal aspecto parcial le alude más adelante con carácter genérico (art. 156.1) y también con un talante instrumental, como fundamento del propio Fondo de Compensación, con la finalidad de corregir desequilibrios económicos interterritoriales y hacer efectivo el principio de solidaridad (art. 158.2), cuya salvaguardia se encomienda al Estado, que ba de velar por el establecimiento de un equilibrio económico, adecuado y justo, entre las partes de territorio español, con particular atención a su competente insular (art. 138.1)”.

Dicho principio actúa como exigencia de un equilibrio económico adecuado y justo entre las distintas Comunidades Autónomas. Manifestaciones concretas de la regulación de la solidaridad se encuentran en el artículo 138.1, en el que el Estado aparece como garante del principio de solidaridad; artículo 149.1.14. ${ }^{\mathrm{a}}$, que atribuye al Estado la competencia exclusiva en materia de "Hacienda General"; artículo 156.1, que recoge el principio de "Solidaridad entre todos los españoles"; y artículo 157.1 c), que regula las asignacio- 
nes presupuestarias para garantizar un nivel mínimo en la prestación de los servicios esenciales y transferencias del Fondo de Compensación Interterritorial, entre otros.

Con arreglo a lo expuesto, las inversiones regionalizables persiguen, de conformidad con el texto Constitucional y con la LOFCA, hacer efectivo el principio de solidaridad interterritorial. Las inversiones directas estatales se configuran como instrumentos al servicio del principio de solidaridad.

El hecho de que Cataluña y Andalucía, hayan establecido en sus Estatutos el criterio que más les interesa a efectos del reparto de las inversiones constituye una medida que repercute en las restantes Comunidades Autónomas y, en definitiva, incide en el conjunto del sistema económico de éstas.

Las Disposiciones que analizamos obligarán al Estado durante siete años a invertir en infraestructuras en una cuantía equivalente "al peso" del PIB de Cataluña o de la población andaluza, en el conjunto del Estado. Actualmente, la población andaluza supone un $17,8 \%$ del total de la población española. Con arreglo a dicho porcentaje, el Estado tendría que invertir en dicha Comunidad un $17,8 \%$ de su presupuesto para infraestructuras. Si el reparto se hiciera siguiendo el criterio del peso del PIB, que la ley de Presupuestos ha empleado para Cataluña en 2007, Andalucía recibiría un 13,7\%, es decir, menos que si atendiera al porcentaje de la población. Por su parte Cataluña, que solo tiene el $16 \%$ de la población nacional, se ha garantizado por vía estatutaria que el Estado invierta durante 7 años el 18,5\% del total, con arreglo a su peso de la Comunidad en el PIB.

Como advirtió el Consejo Jurídico Consultivo de la Comunidad Valenciana en su Dictamen 543/2007 si distribuimos las inversiones estatales en función del peso del PIB regional, la suma dará 100. Si las distribuimos atendiendo al porcentaje de la población, el importe para cada Comunidad Autónoma será distinto, pero la suma también dará 100. Pero si desde cada Comunidad Autónoma se impone al Estado invertir en función del criterio que más le beneficia: (en Andalucía por la población; en Cataluña por el PIB, en las islas por la insularidad, etc) nos encontraremos que la suma de los distintos porcentajes será distinta al 100\% de las inversiones totales del Estado, de forma que no será posible, en términos matemáticos, ajustar las cuentas en materia de inversiones.

También el Consejo Consultivo de la Rioja se ha hecho eco del problema que suscita tales Disposiciones Adicionales, y en su Dictamen 28/2008, advierte que "difícilmente podrán utilizarse, - a elección de cada territorio-, criterios distintos y contrapuestos para proceder a la distribución territorial de la inversión del Estado en las Comunidades autónomas, pues resulta prácticamente imposible realizar tal reparto. La viabilidad del sistema no soporta esa dispersión y contraposición de criterios".

Además, la fijación de un concreto sistema de reparto de las inversiones estatales en los Estatutos Catalán y Andaluz perjudica a las restantes Comunidades Autónomas en la medida en que, a tenor de lo expuesto anteriormente, éstas deberían optar por el mismo criterio (el de la población) o por otro 
u otros que permitieran cuadrar los Presupuesto del Estado al 100\%. Y no a todas las Comunidades les interesa el criterio de la población, como así se ha comprobado en Cataluña que ha optado por el de su peso en el PIB, ni tampoco a todas les interesa el criterio del PIB.

De ello se desprende que el establecimiento a la carta de un método de distribución de inversiones para Cataluña y Andalucía condiciona necesariamente el criterio de reparto a las restantes Comunidades Autónomas cuyas inversiones, además, se limitarán inevitablemente a la parte sobrante del todas las inversiones regionalizables, tras descontar el compromiso de gasto al que se sujeta el Estado en virtud de las Disposiciones Adicionales de los Estatutos Catalán y Andaluz. Ello supone una actuación contraria al principio de solidaridad que ha de regir el reparto de las inversiones estatales entre las Comunidades Autónomas, en atención a las necesidades socioeconómicas de cada una de ellas al tiempo de cuantificar las inversiones.

Las citadas Disposiciones establecen en los respectivos Estatutos criterios de inversión obligatorios para el Estado sin consideración al conjunto de las necesidades de las restantes Comunidades, que se ven obligadas a recibir menos para compensar los incrementos de las Comunidades que como Cataluña y Andalucía predeterminan su criterio de inversión. Cataluña se asegura un 18,9\% de las inversiones del Estado (4,3 más que en el año 2006) y Andalucía un $17,8 \%$ (un 2,1\% más).

El Tribunal Constitucional en la citada Sentencia 13/2007 afirma que "en suma, no existe un derecho de las Comunidades Autónomas constitucionalmente consagrado a recibir una determinada financiación, sino un derecho a que la suma global de los recursos existentes de conformidad con el sistema aplicable en cada momento se reparta entre ellas respetando los principios de solidaridad y coordinación. Por este motivo, habida cuenta de que la cifra de la financiación no es ilimitada y de que su distribución debe efectuarse de conformidad con los intereses generales y en función de los de todos los entes territoriales afectados, no puede pretender cada Comunidad Autónoma para la determinación del porcentaje de participación que sobre aquellos ingresos le pueda corresponder la aplicación de aquel criterio o variable que sea más favorable en cada momento a sus intereses...".

$\mathrm{Y}$ añade, en el fundamento jurídico 9, que "en modo alguno cabe admitir que la determinación del porcentaje de participación en los ingresos del Estado pueda depender de la voluntad de una determinada Comunidad Autónoma.... Conferir carácter vinculante a la voluntad autonómica, no sólo anularía la potestad exclusiva del Estado para configurar el sistema de financiación de las Comunidades Autónomas que considere más idóneo, sino que le privaría, tanto de ejercer sus potestades de coordinación (art. 156.1 CE), como de garantizar "la realización efectiva del principio de solidaridad consagrado en el art. 2 de la Constitución, velando por el establecimiento de un equilibrio económico adecuado y justo entre las diversas partes del territorio español" (art. 138.1 CE). En suma, dotar de carácter vinculante a aquella voluntad sería tanto como conceder un derecho de veto a una Comunidad 
Autónoma sobre el ejercicio de las competencias exclusivas del Estado, permitiéndole bloquear cualquier iniciativa de aquél dirigida a modificar el sistema de financiación (en sentido similar, y con relación a la audiencia previa al Parlamento canario prevista en la disposición adicional tercera CE y en el art. 46 del Estatuto de Autonomía, SSTC 16/2006, F. 9, y 109/2004, de 30 de junio" - doctrina que resulta aplicable mutatis mutandis a los criterios de participación en las inversiones directas del Estado-.

Igualmente resultan significativas las alegaciones vertidas por el Abogado del Estado y recogidas en la citada Sentencia 13/2007, en la que indica que "la masa de recursos que se destina a la PIE debe distribuirse de una forma proporcional atendiendo a las circunstancias socioeconómicas de cada una de las Comunidades Autónomas en un momento concreto, de acuerdo a los factores que el citado art. 13 LOFCA prevé. Sin embargo la Comunidad Autónoma recurrente emplea directamente en sus cálculos el valor absoluto de la variable población, esto es, toma en consideración para determinar el importe a percibir el valor absoluto de una determinada variable, soslayando la masa de recursos a distribuir y la proporción que dicha variable representa con respecto al conjunto de las Comunidades Autónomas con similar nivel de competencias".

Además, en la medida en que dicho compromiso de gasto se establece singularmente a favor solo de Cataluña y de Andalucía, constituye un privilegio en materia de inversiones que infringe el principio de igualdad entre las distintas Comunidades Autónomas y entre todos los españoles, creando privilegios económicos que resultan contrarios al artículo 138.2 de la CE, que establece que "las diferencias entre los Estatutos de Autonomía no podrán implicar, en ningún caso, privilegios económicos y sociales".

Determinados preceptos constitucionales tratan de evitar disfuncionalidades en la actividad económica, que se producirían con la aplicación desigual de los criterios de reparto. Así, el artículo 138.1 de la CE atribuye al Estado garantizar la realización efectiva del principio de solidaridad, velando por el establecimiento de un equilibrio económico, adecuado y justo entre las distintas Comunidades Autónomas. Y el artículo 138.2 prohíbe los privilegios económicos y sociales entre las Comunidades Autónomas. Asimismo, corresponde al Estado la planificación de la actividad económica general. La aplicación desigual de criterios de distribución de las inversiones vulnera el principio de igualdad, a la vez que produce una injustificada discriminación que colisiona con el citado principio de igualdad.

Por otro lado, el Tribunal Constitucional (SSTC. 1/1981, 4/1981, 25/81, entre otras) ha mantenido la existencia de un principio de unidad de orden económico, extraíble de los preceptos constitucionales que delimitan la "ordenación económica de la economía, así como de la competencia estatal en materia de "ordenación general de la economía". Pues bien, tal principio conlleva la homogeneidad y coordinación de las inversiones estatales, como garantía del principio de solidaridad y justa distribución regional de las inversiones. 
El régimen jurídico de tales inversiones, en la medida que forma parte del orden económico estatal, reclama una dosis inevitable de homogeneidad, consecuencia del principio de solidaridad y unidad como indeclinable exigencia de la igualdad de los españoles. El Tribunal Constitucional, en la Sentencia 1/1982, señala que el orden constitucional implica la existencia de unos principios básicos del orden económico que ban de aplicarse, con carácter unitario, unicidad que está reiteradamente exigida por la Constitución, cuyo Preámbulo garantiza la existencia de un orden económico y social justo y cuyo artículo $2 .^{\circ}$ establece un principio de unidad que se proyecta en la esfera económica por medio de diversos preceptos constitucionales, tales como el 128, entendido en su totalidad; el 131.1, el 139.2 y el 138.2, entre otros. Por otra parte, la Constitución fija una serie de objetivos de carácter económico cuya consecución exige la adopción de medidas de política económica aplicables, con carácter general, a todo el territorio nacional (art. 40.1, 130.1, 131.1 y 138.1)”.

Todo ello determina que las Disposiciones Adicionales objeto de nuestra atención resulten contrarias al principio de solidaridad que exigen los artículos 2 y 156 de la CE y 2 de la LOFCA, introduciendo un privilegio a favor de aquellas Comunidades proscrito en el artículo 138.2 CE.

Ello sin entrar en otras consideraciones acerca de la posible infracción del principio de asignación equitativa del gasto público previsto en el artículo 31.2 de la CE así como del de seguridad jurídica consagrado en el artículo 9.3 CE.

\section{II.3. LAS NUEVAS PREVISIONES ESTATUTARIAS SOBRE EL AGUA}

No son pocos los problemas que plantea la regulación de una materia tan controvertida como el agua. Prueba de ello es el rosario de recursos de inconstitucionalidad que se han formulado al respecto por una serie de Comunidades autónomas contra los Estatutos de otras.

Así, el Estatuto de autonomía de la Comunidad Valenciana fue impugnado por las Comunidades de Aragón y de Castilla-La Mancha, que consideraron inconstitucional su art. 17.1 que proclama que:

"Se garantiza el derecho de los valencianos y valencianas a disponer del abastecimiento suficiente de agua de calidad. Igualmente, se reconoce el derecho de redistribución de los sobrantes de aguas de cuencas excedentarias atendiendo a criterios de sostenibilidad de acuerdo con la Constitución y la legislación estatal».

Ambos recursos de inconstitucionalidad fueron desestimados por el Tribunal Constitucional en sus Sentencias 247/2007 y 249/2007"18, fundamental-

18 En las que se aprovechó para resolver también el dilema de si los Estatutos pueden o no contener declaraciones de específicos derechos. 
mente porque la formulación de los derechos que se proclaman en el citado precepto resultan condicionados — -de acuerdo con la Constitución y la legislación estatal», y tal regulación no es ajena al contenido constitucionalmente legítimo de los Estatutos de autonomía, no resultando, por tanto, contrario a la Constitución.

Del Estatuto de Cataluña también se ha atacado por las Comunidades Valenciana, de Murcia y de La Rioja, su art. 117.4, que dispone que:

"La Generalitat debe emitir un informe preceptivo para cualquier propuesta de trasvase de cuencas que implique la modificación de los recursos hídricos de su ámbito territorial».

Al respecto cabe indicar que uno de los objetivos de la planificación hidrológica es precisamente equilibrar y armonizar el desarrollo regional y sectorial, incrementando la disponibilidad del agua, (artículo 38. 1 de la Ley 29/1985, de Aguas, y artículo 40.1 del actual Texto Refundido de la Ley de Aguas, aprobado por Real Decreto-Legislativo 1/2001, de 20 de julio) ${ }^{19}$.

La Exposición de Motivos de la Ley 10/2001, del Plan Hidrológico Nacional, reconoce que "en un país como España en el que el agua es un recurso escaso, marcado por graves desequilibrios hidricos debido a su irregular distribución, la adecuada planificación de la política bidráulica se impone como una necesidad... como un instrumento de superación de la misma".

El eje central de la Ley 10/2001, como expone su propia Exposición de Motivos, lo constituye "la regulación de las transferencias de recursos hidráulicos entre ámbitos territoriales de distintos planes de cuenca". Estas transferencias de recursos hidráulicos vienen impuestas por la irregularidad hidráulica de nuestro territorio nacional, lo que provoca la existencia de regiones que no disponen de recursos hidráulicos propios para satisfacer las demandas actuales que resulta necesario atender, en contraposición con la situación de otras regiones.

Es de señalar que el ciclo hidrológico es único para todo el territorio nacional y se fundamenta en el principio de solidaridad en la utilización y reparto del agua. El Plan Hidrológico Nacional funciona, por tanto, como un todo unitario que se extiende a la totalidad de nuestro territorio, compensando la escasez de determinadas regiones con los excedentes de este recurso en otras. Ello determina que cualquier decisión importante que se adopte en relación con las propuestas de trasvase de cuencas afecte a todo el territorio y puede suponer una afectación en las condiciones de ejercicio de las competencias de distintas Comunidades Autónomas.

Dicho esto, la petición de "informe preceptivo" de forma exclusiva y única a la Generalitat de Cataluña, puede resultar contraria al principio de lealtad institucional y al derecho de participación de las distintas Comunidades Autónomas.

19 Dictamen del Consejo Jurídico Consultivo de la Comunidad Valenciana 633/2006. 
La petición de informe en el ámbito de los procedimientos tiene como finalidad proporcionar al órgano competente información sobre elementos de hecho o técnicos en aras a la adopción de la decisión final. Tales informes, en virtud del principio de objetividad al que están sometidos los poderes públicos y de no arbitrariedad (artículo 9.3 de la Constitución), condiciona la adopción de la decisión definitiva. No se opone a dicha afirmación el hecho de que el informe no sea vinculante ya que, como expresó el Tribunal Constitucional en la Sentencia 118/1998, en relación con el informe preceptivo de los organismos de cuenca en los expedientes de declaración de zonas protegidas, "(...) el informe preceptivo aunque no sea vinculante, de un organismo incardinado en la propia Administración del Estado, exigido como requisito previo para la declaración por la Comunidad Autónoma de zonas protegidas por sus características naturales o interés ecológico condiciona indebidamente el ejercicio por ésta de sus competencias propias (SSTC 36/1994, fundamento jurídico 5.'; 118/1996, fundamento jurídico 22; 197/1996, fundamento jurídico 13). Tal requisito, en cuanto, como decimos, condiciona la competencia autonómica, no encuentra cobertura en competencia estatal alguna...".

Atendiendo a la doctrina sentada por el Tribunal Constitucional, resulta evidente el carácter improcedente a la solicitud de informe preceptivo, única y exclusivamente, de la Generalitat de Cataluña, en todas las propuestas de trasvase de cuencas que suponga una modificación de los recursos hídricos de su territorio, ya que la emisión de dicho informe "condiciona indebidamente" la decisión del órgano competente, que ha de atender en la adopción de sus decisiones al interés general concurrente, y no exclusivamente al de una sola Comunidad Autónoma.

No obsta a ello el hecho de que el informe preceptivo se circunscriba a las propuestas de trasvase de cuencas que conlleven la modificación de los recursos hídricos de su territorio, ya que, como se ha indicado anteriormente, el ciclo hidrológico es único para todo el territorio nacional, sin que tales recursos hídricos sean susceptibles de territorialización, ni patrimonialización, por parte de las Comunidades Autónomas. La decisión que pueda adoptarse en materia de trasvase de caudales, afecta, en definitiva, a todo el ciclo hidráulico y al conjunto de las Comunidades Autónomas.

Téngase en cuenta, por otro lado, que circunscribir la petición de informe preceptivo a una única Comunidad Autónoma, cuando existen otras Comunidades interesadas en las propuestas de trasvase de cuenca, vulnera el principio de igualdad, así como el derecho de participación de las restantes Comunidades Autónomas implicadas, entre ellas, las recurrentes de inconstitucionalidad.

Desde el momento que el ciclo hidrológico es único y afecta a todo el territorio nacional — con sus correspondientes implicaciones- cualquier decisión de trascendencia que se adopte en relación con los trasvases de cuencas produce una afectación automática en las distintas regiones de nuestro territorio. Ante esta situación, con la finalidad de coordinar la actuación de los poderes públicos en materia de aguas se arbitran mecanismos tan impor- 
tantes y eficaces como la participación y la colaboración de las distintas Administraciones Públicas afectadas y no exclusivamente de la de una de ellas.

La omisión del informe preceptivo de las restantes Comunidades Autónomas puede vulnerar su derecho de participación en las cuestiones que inciden en su ámbito competencial. Un derecho de participación que le viene reconocido implícitamente en la Constitución Española.

El deber de dar participación a las Administraciones Públicas afectadas en aquellas decisiones que vaya a adoptar otro poder público viene exigido por el principio constitucional de lealtad institucional y el de buena fe, en el ejercicio y actuación de los poderes públicos. En este sentido, el Tribunal Constitucional recuerda en su Sentencia 40/1998 que "el principio de colaboración entre el Estado y las Comunidades Autónomas está implícito en el sistema de autonomías (SSTC 18/1982, entre otras)"; y que "la consolidación y el correcto funcionamiento del Estado de las autonomias dependen en buena medida de la estricta sujeción de uno y otras a fórmulas racionales de cooperación, consulta, participación, coordinación, concertación o acuerdo (...)”. En la STC 18/1982 se dice, además, que el deber de colaboración dimanante del general de auxilio recíproco entre autoridades estatales y autónomas, "no es menester justificar en preceptos concretos, se encuentra implicito en la propia esencia de la forma de organización territorial del Estado que se implanta en la Constitución, aunque no es ocioso recordar que el principio de coordinación, en relación con las Comunidades Autónomas, se eleva por la norma fundamental a la consideración de uno de los principios de actuación (artículos 103.1 y 152)». En igual sentido, SSTC 209/1990, 46/1990, 64/1990.

Aunque pudiera entenderse que el Plan Hidrológico Nacional —como eje central del trasvase entre cuencas - no afecta directamente a las competencias asumidas por las Comunidades recurrentes en el sentido de "suma o serie de competencias asignadas en sus correspondientes Estatutos y en la Constitución", lo cierto es que sí afecta al ámbito de sus intereses políticos específicos - trasladando aquí la doctrina del Tribunal Constitucional acerca del concepto de "ámbito de autonomía" del artículo 32.2 de la Constituciónasí como a las condiciones esenciales del ejercicio de competencias como las de ordenación del territorio y del paisaje, medio ambiente, pesca, agricultura, aprovechamientos hidráulicos y el propio fomento del desarrollo de la Comunidad Autónoma, etc. Así pues, resulta evidente la necesidad inexcusable de la participación de las Comunidades recurrentes.

La importancia del informe establecido en el artículo 117.4 del Estatuto Cataluña resulta igualmente de la Sentencia del Tribunal Constitucional $35 / 1984$, en la que la falta de un informe previo del Parlamento de Canarias resultó determinante en el recurso de inconstitucionalidad interpuesto por aquél contra el Real Decreto-Ley 1/1983, de 9 de febrero, por el que se derogó la exacción sobre el precio de las gasolinas de automoción. El Tribunal Constitucional estimó el recurso aplicando "la doctrina existente, emitida a propósito del procedimiento administrativo" sobre la emisión de informes o audiencias preceptivas: se había omitido, improcedentemente, la audiencia al 
Parlamento de Canarias. En igual sentido la STC 137/2003, declaró la inconstitucionalidad del Decreto-Ley 12/1995, sobre medidas urgentes en materia presupuestaria, financiera y tributaria, por ausencia de un trámite esencial, pese a estimar que concurría la extraordinaria y urgente necesidad.

Dichas Sentencias reflejan la trascendencia de la omisión de trámites preceptuados en los correspondientes Estatutos de Autonomía.

Téngase en cuenta, por otro lado, que la participación de las Comunidades Autónomas y demás entes interesados en los trasvases de cuencas corresponde a los organismos de cuenca, órganos colegiados en los que prevalece el interés general sobre el particular de cada uno de sus componentes. Resulta, por tanto, contrario al principio de lealtad institucional y al de participación de las Comunidades Autónomas exigir, de forma singular, la emisión de un informe preceptivo en materia de trasvase de caudales, como una especie de trámite de audiencia a una sola Comunidad Autónoma.

El principio de lealtad institucional y buena fe debe prevalecer en todo caso, por lo que la petición de informe preceptivo exclusivamente a la Generalitat de Cataluña se estima contrario a tales principios consagrados en el Texto Constitucional en la medida en que, como ha señalado el Tribunal Constitucional en la citada Sentencia 118/1998, condiciona indebidamente el ejercicio de la competencia por parte del órgano decisor en materia de trasvase de caudales.

Además, al Estado compete, de forma exclusiva —artículo 149.1.22. ${ }^{\text {a de }}$ la Constitución - "la legislación, ordenación y concesión de recursos y aprovechamientos hidráulicos cuando las aguas discurran por más de una Comunidad", de lo que se infiere que es el Estado el que debe disponer libremente el régimen de los trasvases, estableciendo la pertinente regulación y modificándola cuando así lo estime conveniente. Y ello no puede ocurrir si el ejercicio de tal competencia se condiciona desde una norma que, aunque estatal desde la perspectiva de su aprobación, es indisponible para el Estado, pues sabido es que el Estado no puede, por sí solo, modificar un Estatuto de autonomía.

Es por tanto, en una Ley ordinaria, y no en un Estatuto aprobado por Ley Orgánica - y ni tan siquiera, en esta clase de Leyes- en la que debe regularse cuanto afecta a la ordenación de los recursos hidráulicos de aguas que discurran por más de una Comunidad, motivo que abona también la inconstitucionalidad del precepto que comentamos.

Cabe hacer referencia, a que también contra el Estatuto de autonomía de Andalucía se ha formulado recurso de inconstitucionalidad por Extremadura, al estimar contrarios a la Constitución los artículos 50 y 51 sobre competencias en materia de agua y sobre la cuenca hidrográfica del Gualdalquivir.

También Extremadura ha impugnado ante el Tribunal Constitucional el art. 75.1 del Estatuto de Castilla y León, sobre competencias sobre la Cuenca del Duero.

Y, por último, el Estatuto de Aragón ha sido recurrido por La Rioja por la regulación que contiene en relación con las competencias en materia de aguas. 


\section{III. ¿HACIA LA DECONSTRUCCIÓN DEL ESTADO AUTONÓMICO?}

Ya he afirmado que la Constitución no prefigura el Estado autonómico, pero contiene las bases y principios sobre los que aquel se podía construir. También, he afirmado que el desarrollo del Estado autonómico tiene carácter dinámico, lo que quiere decir que no puede quedar petrificado, sin posibilidad alguna de acomodación a nuevas exigencias que plantea el discurrir del tiempo, todo lo cual no impide que el modelo requiera de una estabilidad que impida movimientos bruscos que pongan en entredicho el propio modelo y traten de obviar las bases y principios constitucionales.

También he puesto de manifiesto que la constitución del Estado autonómico ha pasado por diferentes etapas en las que se ha ido perfilando y perfeccionando, siempre sobre la base de grandes Acuerdos entre las principales fuerzas políticas. Ello ha dado como resultado uno de los Estados políticamente más descentralizados del mundo, y una transformación de España, a mi juicio, altamente positiva desde el punto de vista político, económico, social y cultural.

Sin embargo, durante la VIII Legislatura se han producido una serie de acontecimientos en este ámbito que han alterado lo que se ha conocido como la "paz social autonómica". No ya tanto por los debates originados en torno al "Plan Ibarretxe", sino, y sobre todo, por la aprobación de la reforma del Estatuto de Cataluña, cuyo contenido, en términos generales, también ha atendido Andalucía en la reforma del suyo.

Aparte las aspiraciones soberanistas que en algunas, -muy pocas-, Comunidades autónomas se han venido percibiendo, durante la actual etapa constitucional, con muy desigual intensidad, estimo que fue la equiparación competencial derivada de los Pactos de 1992 la que ha sido el detonante que ha llevado a acometer profundas reformas de los Estatutos de autonomía durante la VIII Legislatura. Nótese que a la reforma del Estatuto valenciano ${ }^{20}$, y a la del Estatuto de Cataluña, siguieron las de los Estatutos de Andalucía, Baleares, Aragón y Castilla-León, y están en ciernes las de otras Comunidades $^{21}$. Me permito dudar de si eran necesarias reformas tan profundas que, en realidad, han desembocado en nuevos Estatutos de autonomía y me temo que por esa senda discurrirán las demás Comunidades autónomas.

Sólo he querido detenerme en el análisis de tres cuestiones —-blindaje de competencias, inversiones del Estado predeterminadas en los Estatutos, y regulación del agua-, que ponen de manifiesto la distorsión del sistema hasta ahora vigente. Pero no son las únicas. El Tribunal Constitucional tendrá que abordar otras muchas.

Como consecuencia de todo ello hemos oído y leído que lo que se ha producido, en realidad, es una mutación constitucional e, incluso, una modi-

20 Desde luego necesaria, pues el anteriormente vigente de 1982 aun contenía limitaciones al autogobierno derivadas de los Pactos Autonómicos de 1981.

21 Durante la IX Legislatura se han presentado en el Congreso de los Diputados los proyectos de reforma de los Estatutos de Castilla-La Mancha y Extremadura. 
ficación implícita de la Constitución; o una reinterpretación de la misma. No estoy de acuerdo con tales opiniones.

La mutación constitucional supone una inevitable acomodación del derecho constitucional a la realidad constitucional, una transformación de la configuración del poder político, de la estructura social o del equilibrio de intereses, sin que tal transformación quede plasmada o reflejada en el texto constitucional, que permanece intacto. Nada de esto ha ocurrido. La acomodación de la realidad a los intereses particulares de grupos políticos minoritarios, aún acompañada de la permisibilidad de alguno mayoritario, no puede considerarse nunca una mutación constitucional. La Constitución es una norma jurídica que se debe cumplir en sus propios términos y si lo que se pretende es alterarla o cambiarla, debe seguirse el procedimiento de reforma en ella previsto.

Por ello tampoco entiendo a quienes sostienen que, en realidad, lo que se ha producido es una reforma implícita de la Constitución. No caben en nuestro ordenamiento jurídico constitucional reformas implícitas de la Constitución y, desde luego, no mediante un Estatuto de autonomía. La reforma se ha de acometer, necesariamente, por los cauces de los artículos 167 y 168 de la Constitución. No se puede reformar de otra forma. Si una norma contradice la Constitución, no la está reformando, simplemente la está vulnerando.

La reforma de la Constitución es una garantía de su vigencia y cumplimiento. Una norma que no pudiera acoplarse a las necesidades que el transcurso del tiempo a la realidad política van planteando encerraría en sí misma la semilla de la desconfianza y el rechazo.

Es difícil predecir las circunstancias en que es aconsejable la reforma de una Ley fundamental. Loewenstein, apunta a las modificaciones que experimentan las relaciones sociales, económicas o políticas como las responsables de que una norma, que parecía razonable y suficiente en el momento de su creación, haya perdido su capacidad funcional y tenga que ser, por lo tanto, completada, eliminada o acoplada de alguna manera a las nuevas exigencias en interés de un desarrollo sin fricciones del proceso político ${ }^{22}$.

Es posible que la Constitución española deba ser reformada. Pero no para acomodarse a las disposiciones de un Estatuto de autonomía. Esto sería, jurídicamente hablando, un disparate. Quizás fuera conveniente para delimitar con mayor concreción las competencias del Estado y las de las Comunidades autónomas, entre otras cuestiones.

Desde luego no cabe hablar, tampoco, de una reinterpretación de la Carta Magna si da como resultado un texto legal contrario a la misma. Parece que la interpretación o reinterpretación solo es válida desde la perspectiva de una minoría de los españoles, lo que resulta sencillamente absurdo. La finalidad de la interpretación consiste en averiguar el sentido de la norma, no en adecuarla al propósito o deseo consciente del intérprete.

Parece, más bien, que lo que se está pretendiendo es una deconstrucción del Estado autonómico, un desmontaje analítico de los elementos que 
constituyen su estructura conceptual derivada del gran pacto constitucional de 1978.

Es incorrecto el planteamiento de que nuestra Constitución es un texto totalmente abierto en el que tan solo se han plasmado ciertos principios, con la pretensión de que la constitucionalización del modelo de Estado se lleve a cabo por medio de los Estatutos. Como ha advertido Carreras ${ }^{23}$, la parte no puede condicionar al todo. Si así fuera, diecisiete partes (las diecisiete Comunidades autónomas) podrían de condicionar de forma distinta al todo (el Estado) y la confusión se instalaría como norma general de nuestro sistema jurídico, político y social. Además, tal pretensión de que sean los Estatutos los que configuren el modelo de Estado desde la perspectiva territorial corre el peligro señalado por Alvarez Conde ${ }^{24}$, de que supondría una radicalización del principio dispositivo y de los elementos asimétricos y podría suponer la aparición de toda una serie de disfunciones que afectarían al funcionamiento del Estado en su conjunto.

Lo más sorprendente es que esa deconstrucción del Estado autonómico viene propiciada por partidos minoritarios y por coyunturales alianzas políticas. Ahora, la curiosidad del jurista persa al que se refería Cruz Villalón en su famoso artículo, debe haber quedado desbordada produciéndole un aturdimiento difícil de superar.. Desgraciadamente todo ello ha propiciado que vuelvan a alzarse voces, ya en el olvido, que ponen en entredicho las bondades del Estado autonómico; incluso como Carreras ${ }^{25}$ ha señalado, se han acentuado las dudas sobre la viabilidad y eficacia de este modelo de Estado.

Por ello, ahora más que nunca son necesarias altas dosis de cordura para evitar que tal deconstrucción se consume. El Tribunal Constitucional es quien más puede aportar al efecto.

\section{TitLE: The deconstruction of the Autonomous State.}

AвSTRACT: During the 8th Legislation a series of evens has taken place in the area of State territorial configuration which has altered what has become known as "autonomous social peace". The reforms of some Statutes of autonomy had to be preceded, as in 1981 and 1982, by a pact between the main political forces. Singularly, the reform of the Statute of Catalonia poses the problem of its adaptation to the Constitution. Subjects such as the protection of competences, clauses on investments or water previsions deserve specific analysis. If this not resolved by the Constitutional Court, we will witness the collapse of the autonomous State, which, curiously, would be caused by minority parties and temporary political alliances.

RESUMEN: Durante la VIII Legislatura se han producido una serie de acontecimientos en el ámbito de la configuración territorial del Estado que han alterado lo que se ha conocido como la "paz social autonómica". Las reformas de algunos Estatutos de autonomía debieron estsar precididas, como en 1981 y en 1992, de un pacto entre las principales fuerzas políticas. Singularmente, la reforma del Estatuto de Cataluña plantea el problema de su adecuación a la Constitución.

23 DE CARRERAS, F. «Inconstitucionalidad contagiosa». La Vanguardia, 1.10.2009.

24 ÁLVAREZ CONDE, E. Reforma constitucional y reformas estatutarias, Iustel, 2007, pág. 220.

25 DE CARRERAS, F.. La Vanguardia, 21.05.2009, pág. 20. 
Temas como el blindaje de competencias, las cláusulas sobre inversiones o las previsiones sobre el agua merecen un análisis específico. Si no se remedia por el Tribunal Constitucional, asistiremos a una deconstrucción del Estado autonómico, curiosamente proporcionada por partidos minoritarios y por coyunturales alianzas políticas.

KEY WORDS: Reform of the Statutes and respect of the Constitution. Protection of competences. Clauses on investments. Water regulation. Breakdown of the autonomous State.

Palabras clave: Reforma de los Estatutos y respeto de la Constitución. Blindaje de competencias. Cláusulas sobre inversiones. Regulación del agua. La deconstrucción del Estado autonómico. 